\title{
A Review of CIO's Role in Increasing Competitive Advantage
}

\author{
Rizwan Ahmad \\ Columbia University \\ Email: ra2770@columbia.edu \\ (https://orcid.org/0000-0002-1715-3906)
}

\begin{abstract}
As we all know that IT is critical to business growth as it enables business model to scale and enhances the ability of the organization to successfully manage the complexity of the organization and its various processes. This paper attempts to review the CIO's role in increasing and maintaining the competitive advantage of the company. The paper discusses the functional and technical scope of the CIO's role based on the operating model, enterprise architecture and IT engagement model. The paper further discusses about how the role of CIO has evolved in recent years and continues to evolve even further keeping in mind the complexities of the business and its processes. Finally, the paper discusses about how CIOs need to step up to make a constructive effort in the era of constantly evolving technological landscape and make an impact in improving the operational efficiency of the company.
\end{abstract}

Keywords: CIO's role, operating model, enterprise architecture, IT engagement model, IT innovation, IT security risks.

\section{Introduction}

According to a recent International Study (Pose, 2011), IT is critical to business growth as it enables business model to scale and enhances the ability of the organization to successfully manage the complexity of the company and its various processes. Companies, whose businesses processes are scalable, are more likely to overcome obstacles to growth and quickly capture the business opportunities that may come across it and are easily able to differentiate from the competition. These companies have employed technology in their business processes so that they can efficiently and reliably execute the core operations of the company. Business processes and decision-making systems are inevitably linked with myriad ways. "IT is consistently correlated to changes in the way people work and how their performance is measured, controlled and reported" (Brynjolfsson, 2003, n.a). Even as companies "attempt to hire more skilled and educated workers, they must also make organizational adaptations to distribute information processing tasks" (Brynjolfsson, 2003, n.a).

Many companies have used IT to gain competitive advantage but defining, measuring and maximizing the value remains incredibly tough. Analysing their approaches to IT enabled practices in their organization enables us to show how such practices can improve economic performance. At a time, "when costs are continually being squeezed, there is more pressure to demonstrate the business value of technology" however different business sectors are continuously adopting the cultural change from the costs of IT to the value of IT at increasingly fast changing rates (Computerweekly.com, n.d). This foundation and later transformation process makes the role of new CIO extremely crucial and indispensable for creating organization's road map to harness IT resources for all business resources and its transformation by overcoming numerous barriers such as rigid processes, technology infrastructures that are not aligned with agile engaging customers. As IT costs are coming down, the pressure to show the value of IT is increasing. For this reason, the role of CIO in communicating the value of IT to all its stakeholders becomes incredibly important in emphasizing operations while aligning it with business objectives, using metrics to see how business is performing and what steps needed to be taken to improve the performance of business in addition to teaming on strategy and getting staff comfortable on the use of IT in business (CIO Executive Council, 2009).

\section{Functional And Technical Scope of CIO's Role}

The scope of the position of the Chief Information Officer, or CIO, may vary depending on the size of the enterprise. This role has emerged from an information technology (IT) position to one that encompasses developing the IT strategic policies to ensure that the computer systems have the capability to assist the enterprise in attaining its objectives and goals. In some enterprises, the CIO is a member of the Board and participates as a contributor in formulating the strategic goals. The CIO also educates the members of executive management and the employees in topics concerning the business value and potential risks associated with IT. The CIO bears the responsibility of ensuring that the IT needs of the enterprise are met to provide business continuity in all related areas and, when the enterprise is large enough, the CIO delegates certain responsibilities to other staff members, such as desktop technicians and network administrators (Rouse, n.d.). 
Hence CIO is the key driver of the most companies. In order to be the key driver of such transformational changes, CIOs have to focus on the following three key disciplines:

An Operating Model (Ross, Weill, \& Robertson, 2006)

It is the necessary level of business process integration and standardization for delivering products and services to customers. Integration forces a common understanding of data across various business units and process standardizations create efficiencies across business units. There are four types of operating model as given below:

Diversification. Business units in diversified companies offer different products and services to different customers with limited control of central management over these business units.

Coordination. A coordination company share one or more of products, customers, suppliers or/and partners and may include integrated customer service, transparency across supply chain processes and cross selling.

Replication. Replication model grants autonomy to business units but runs operations in a highly standardized fashion and is dependent on global innovation for the overall company and on the efficiency of all business units.

Unification. The unification companies are tightly integrated around a standard set of processes by integrating data and driving variability out of business processes thus maximizing customer service and efficiency.

\section{Enterprise Architecture (Daniel, 2007)}

The CIO is responsible for aligning a business's strategic vision with its information technology in order to develop and implement the enterprise architecture (EA). As the corporate environment has expanded to often encompass international entities, it is imperative to provide cohesive solutions to ensure business continuity. As such, the CIO must be able to differentiate between various types of learning in order to ensure the relative consistency between various technological artefacts in addition to having the ability to maintain this consistency in the event of changing learning types. Companies go through four stages in learning about how to use enterprise architecture approach in designing business processes as given below (Ross, Weill \& Robertson, 2006):

Business Silos. Companies look to maximize individual business functional needs.

Standardized Technology. Provides IT efficiencies through technology standardization.

Optimized Core. Provides company-wide data, process, and standardization as appropriate for the operating model.

Business Modularity. Companies manage and reuse loosely coupled IT-enabled business process components to preserve global standards while enabling local differences.

These learning types are obtained through the knowledge and skill sets of the various individuals that contribute to the development of the EA as it applies to the objectives of the enterprise. This requires knowledge of the business procedures to determine that all models and physical objects have been considered, developing an understanding of the levels of granularity changes within the EA, and if permanent changes and temporal changes are distinguishable as well as if proposed changes will present a high impact or low impact effect. The $\mathrm{CIO}$ must have the ability to determine if there are incompatibilities between the EA requirements and those presented through the business process requirements as well as the ability to determine alternative solutions (Kirikova, 2015).

IT Engagement Model (Ross, Weill \& Robertson, 2006)

IT engagement model is the system of governance mechanisms that ensure business and IT projects achieve both local and companywide objectives. The IT engagement model influences project decisions so that individual solutions are guided by the enterprise architecture. This model influences project decision so that the individual solutions are guided by the enterprise architecture. As the company's architecture matures, the new CIO's role evolves and must comprise the following key skills:

- Detailed knowledge of how the business functions,

- Ability to facilitate innovations off new platform,

- Understanding the strategic benefits of architecture,

- Understanding the architecture as a business enabler,

- Ability to work with top management team to establish basic governance,

- Ability to manage large organizational change efforts,

- Ability to manage large central budget,

- Credibility with business units and functional heads, 
- Technical knowledge to help with standard decisions,

- Ability to delegate ownership of key process and data modules while still ensuring adherence to standards, etc.

\section{Discussion}

The role of CIOs, now a days, is at the cross-road as some believe that spending in IT does not bring competitive advantage because of the lingering disaffection from IT from Internet bust (Broadbent \& Kitzis, 2004). On the other hand, IT is gaining renewed ground because of executive's desperation for innovation. Hence, businesses need CIOs who are leaders, and can transform organizations and processes based on a clear vision of the fast-changing future. This transformation begins with CIOs' vision for IT enabling their enterprise. Thus CIOs have to adopt strategies that will help in transforming the business strategies and process and will bring innovation to the fold for attaining competitive advantage in the long run. When combined with the business strategy, these capabilities can then be used to identify the technology platforms and tactical activities required to enable them. The synthesis of these activities will enable to create a cohesive vision for the organization for taking the next leadership steps (Broadbent \& Kitzis, 2004).

Hence new CIO leaderships focus on both Demand-side and Supply-side functioning of CIOs. On the supply side, CIOs do have the formal authority that comes from their role in the organization as the senior information technology executive. Developing the desired operating model for the IT function, determining which activities to outsource to third parties, and managing enterprise IT risks are illustrative of supply side activities. On the demand side, CIOs must lead as peers, colleagues, and sometimes subordinates. For example, when seeking to improve businesses processes or enable adoption of a new CRM platform, the CIO typically needs to exert his or her influence through persuasion and does not have formal authority over all required stakeholders and supporting systems. According to Broadbent \& Kitzis (2004), new CIO leaders will develop and identify all the opportunities for the specific opportunities and will position themselves and the enterprise to move to the next level of performance. New CIO leaders will not only unlock the business and information intelligence but will also take a leading role to influence and coach about the potential business use of particular technology (Broadbent \& Kitzis, 2004).

It has become incredibly important for IT investments to create value in business and to convince all the stakeholders about want values it brings. Unless the IT becomes the mainstream business activity of the organization, the value it is creating, is not easy to estimate (Computerweekly.com, n.d). Since effective engagement between the business and the IT value needs to be maintained for the survival of IT function, CIOs must be able to maintain and analyse the value of IT operations relative to their financial costs. "It is important to measure not only the services that are used, but also the business results that come from their use" (Computerweekly.com, n.d). To understand how IT creates value for the organization, CIOs and the entire IT team must be able to first understand who the organization's customers are, what they value, how the organization plans to create profits by providing that value, and how the organization intends to deliver that value in a way the competition cannot mimic. To answer these questions, the CIOs must have the organization define its business model and strategies. To be successful, the organization's business model and strategy need to be complementary (Burg \& Singleton, 2005). CIOs must follow the following steps in order to create value (Hunter \& Westerman, 2009):

- Business executives should not have to work to see the good side of IT performance. CIOs who are striving to deliver better value need to make it clear that they know what the problems are and are working hard to improve them.

- CIOs must report IT's operational efficiency in terms of essential services and outcomes that are visible to the rest of business by linking the cost of IT operations to the quality and volume of service followed by benchmarking the costs and performance and thereby inviting comparison to peer organization.

- CIOs must be able to create a virtuous cycle that visibly maximizes the value of investments in IT thereby improving the outcomes of each initiatives and creating capabilities that will increase learning and value with each new project.

- CIOs must indicate that the top executives understands and appreciates the value of IT and CIOs become a business leader, and not only an expert in solving problem in technology and operate as a peer in an executive team providing value beyond IT itself.

Hence, in order to enhance IT's values among all the stakeholders, new CIOs need to step up to make a constructive effort to improve communication among the IT \& non IT workers. New CIOs must have the ability of dedicated communicator so that he/she can transform how information is transmitted and received and will be able to understand and recognize different sets of stockholders - internal management, business users, the internal IT community and external parties- and must be able to look into various sets through different eyes. The CIOs must develop a clear vision of the objectives of the enterprise as well as knowing the limitations to their role within the company. This entails establishing relationship with executives within the enterprise and 
establishing clear lines of communication to further develop the understanding of the expectations of others (Bloch \& Willmott, 2012). The CIOs should participate in the prioritization of the objectives of the enterprise to ensure that the technological artefacts have the ability to accomplish the objectives. The CIOs must also develop a thorough understanding of the use of technology in the specific industry to determine the value created and provided as well as understanding the risks associated with technology in order to develop a cohesive plan that encompasses numerous levels, including the associated costs with technological advances and staffing, the service levels provided, the number of employees needed to support the enterprise, IT projects, and IT health focusing on the existing architecture, capabilities, culture, and delivery. The CIOs have the responsibility to establish a team that can assist the enterprise with achieving its goals and objectives even when circumstances require unexpected changes as well as develop relationships built on respect and effective communications (Bloch \& Willmott, 2012).

Finally, as information technology pervades our society and directs the core process of the business strategies, it also gives rise to a number of social problems including loss of privacy, identity thefts, computer crimes, global outsourcing of job, intellectual property loss, data breach etc. There are three main objectives for information technology security-confidentiality, integrity and availability of data. Hence information technology security has become the challenge of balancing the demands of users verses the need for data confidentiality and integrity, which has also made the job of CIOs extremely crucial. Between IT-regulated laws and governance regulations, CIOs have to take care of many more legal issues than ever before such as compliance regulations, privacy rules and data protection. There are number of ethical and legal issues that need to be managed by companies as it relates to IT enabled initiatives and its implementation in the organization. There are four major areas of security and risks concerns, CIOs must be aware of (Durbin, 2014):

(a) BYODs and Cloud Threats

(b) Privacy and Data Breach Regulations

(c) Data Security Threats

(d) IT failures

Hence the CIOs must manage their IT response to new risks within the context of risk management program, in addition to making sure that, with the help of senior executives in the company, all IT initiatives are compliant with Sarbanes-Oxley Act (SOX) or/and any other legal and ethical standards (IT governance ......, n.d) depending upon the geographical and cultural locations.

\section{Impact}

CIOs must be able to exercise strong organizational discipline to build and leverage a strong foundation, as mentioned above, in order to initiate change from the top and remove barriers. First CIOs should be able to identify the appropriate operating model before linking strategic vision of the company with its information technology in the form of Enterprise Architecture for soothing customer experience (Daniel, 2007). They must have the ability to manage a matrix-pack of often entrenched and silos technologists, and should be having a deeper understanding of the business and interpersonal skills (Heller, 2011). In order to map the credible enterprise architecture, the CIOs should not skip any of the four stages, as mentioned above, but incrementally builds and leverages the capabilities. Subsequently CIOs should follow the following steps (Brynjolfsson, 2003; Hunter \& Westerman, 2009):

- Develop measures of IT, productivity and organizational characteristics,

- Compare practices with effective IT users,

- Adopt a change management process,

- Clear expectations for benefits,

- Baseline measurement of the financial or operational performance areas that are targets of the initiatives,

- A Structural post-implementation review process and team-building, and

- Effectively and efficiently communicate business results and value to the top business executive team and board of directors.

In many instances, the CIOs report to the Chief Executive Officer (CEO), who often considers IT to be a method of initiating corporate growth through the development of a competitive advantage by applying measures to ensure efficiency. The CIOs are often expected to provide innovative solutions to complex issues regarding the use of IT to assist the enterprise with becoming more strategic while adding values. In these areas, the contribution of CIOs consists of assisting with designing and managing the innovation process as a key member of the executive committee providing strategic business management and through the development and implementation of the technology necessary to propel innovative practices (Baya, Gruman, \& Mathaisel, 2011). The design process provides focus on four deliverables consisting of the following elements to increase efficiency while providing innovative solutions. The first deliverable consists of common nomenclature to 
ensure that all parties in the process have an understanding of the terminology used, especially when considering that each department, such as sales, marketing and market research, and programmers, utilize terminology that applies to that area of expertise. Common nomenclature provides clarity to the objectives as well as the course of action and reduces the risk of potential confusion. Digital interfaces allow CIOs to redefine the manner in which the innovation process progresses throughout the enterprise to provide digital integration to streamline the process through the application of an end-to-end design. The third deliverable introduces new processes that are technology-enabled. The new process should work in conjunction with the users to automate common tasks, such as providing data feeds to import credit card usage for business purposes into expense reports, to reduce the number of errors and omissions. This provides a method of developing and implementing opportunities for innovation that provide solutions for systematic issues. Lastly, continuous monitoring and improvement is provided to establish measures of success and failure to ensure that the process is working as anticipated, thereby providing improvements to reduce the number of failures while increasing the amount of success. This requires determining the appropriate metrics to capture the data necessary to measure the effectiveness of the methods applied (Baya, Gruman, \& Mathaisel, 2011).

As technology continues to advance at a rapid pace, the role of the CIOs are changing as well. The CIOs are now often perceived as being the individual within an organization that wields the most power to implement change. This is the result of emerging technologies, including software as a service (SaaS), cloud services, and big data as well as outsourced services, which has changed the manner in which technology is used and supported. As such, the CIOs no longer serve as the authority concerning the manner in which computer systems and the infrastructure work and have expanded to encompass a leadership role that requires the coordination and management of external companies and suppliers as well as internal staff. As relationships with more external companies are developed to provide services in key areas, the internal staff is afforded the ability to transition from a more rigid structure to flexible collaboration in which innovation is a key factor. The CIOs must then address the challenges of a changing environment through embracing collaboration to ensure that the corporate objectives are met that develops further understanding of the enterprise in the areas of business strategy, customer offers, finances, and processes, allocate financial resources rationally by determining how IT can add value to the enterprise, and considers the team by developing realistic expectations to be able to adapt accordingly (Baldwin, 2015).

Finally, CIOs should be able to draw a training plan for IT and non-IT employees for professional development to generate expected benefits of new systems (Baldwin, 2015). Hence strong foundation is very important for successful implementation of enterprise architecture followed by IT governance that will align strategic vision of the company with its IT objective thereby maximizing the business performance and hence the customer experience. Since there are growing number of technology-related risks such as data-protection and IP protection and growing number of such compliant regulations, it is CIOs' job to determine that, during and after the strong foundation for implementing IT enabled initiatives that will align with the company's vision and business objectives, must conform to all the legal and ethical regulation as conformed by any regulatory bodies (Baldwin, 2015).

\section{Conclusion}

The CIO plays an important role in any organization, as this individual is responsible for all things related to information technology. The advances in IT necessitate flexibility within the role of CIO as it is transitioning from one of upper management to being one who provides the vision for the enterprise, the CIO must expand their skill set beyond the knowledge of all IT-related things to encompass other areas, including product development, financial, and marketing, to develop an understanding of how IT can enable and further the ability for all departments within the enterprise to work together to achieve the objectives and goals of the company. As technology continues to evolve, the role of the CIO will continue to evolve as well. Hence new CIOs must develop the authority to bring changes and innovate in this changing environment. By adopting the above strategies will not only assist the efforts to develop the effective IT strategy but will also help to create shared expectations about the role of IT within the organization by having conversations with business colleagues about technologies and the investments required to implement and sustain it, thereby beginning the process of informing and shaping expectations. This will lead to transformational change in the organization by integrating business measures and IT measurement and deliver on the promise of IT and information to yield real, measurable and dependable business results.

Finally, on order for smooth functioning of his responsibilities as a CIO, the new $\mathrm{CIO}$ will also have to have an excellent and healthy professional relationships with CISOs (Chief Information Security Officer) who are responsible for identifying, developing, implementing and maintaining processes across the organization to reduce information and information technology (IT) risks and to maintain regulatory compliance. Further research should be conducted on how, and to what extent, CIO's role can be expanded so as to include the Chief Information Security Officers (CISOs) within its fold so that a better liaison can be maintained in order to eliminate or mitigate the cyber-security risks within the organization. 


\section{ACKNOWLEDGEMENT}

I would first like to thank Prof. Art Langer of the School of Professional Studies at Columbia University in the City of New York. The door to Prof. Langer's office was always open whenever I ran into trouble or had a question about my research and writing. He consistently allowed this paper to be my own work, but steered me in the right the direction whenever he thought I needed it.

I would also like to thank Prof. Chrisanthi Avegrou of the Department of Management at London School of Economics \& Political Science. Without her passionate participation and input, the essay could not have been successfully completed.

This research did not receive any specific grant from funding agencies in the public, commercial, or not-forprofit sectors.

Finally, I must express my very profound gratitude to my parents and to my siblings for providing me with unfailing support and continuous encouragement through the process of researching and writing this paper. This accomplishment would not have been possible without them.

\section{DECLARATION OF INTERESTS STATEMENT}

The author has no conflicts of interest to declare.

\section{References}

[1] Baldwin, H. (2015, June). The rapidly changing role of the CIO. Computer Weekly.com. Retrieved from http://www.computerweekly.com/opinion/The-rapidly-changing-role-of-the-CIO Last Accessed December 13, 2018

[2] Baya, V., Gruman, G., \& Mathaisel, B. (2011). The Strategic CIO's new role in innovation: Innovation is the next frontier for all CIOs, and now is the time for the CIO to prepare and take action. PwC's Technology Forecast: A Quarterly Journal, 2, pp. 44-53.

[3] Bloch, M., \& Willmott, P. (2012, December). The first 100 days of a new CIO: Nine steps for wiring in success. McKinsey Digital. Retrieved from http://www.mckinsey.com/insights/business_technology/the_first_100_days_of_a_new_cio_nine_steps_for_wiring_in_success Last Accessed December 14, 2018

[4] Broadbent, M., \& Kitzis, E. (2004). The New CIO Leader. Setting the Agenda and Delivering Results. Boston, Massachusetts: Harvard Business Review Press.

[5] Brynjolfsson, E. (2003, July). The IT Productivity Gap. Optimize Magazine. Issue 6. Retrieved from http://digital.mit.edu/erik/Optimize/pr_roi.html Last Accessed December 14, 2018

[6] Burg, W.D., \& Singleton, T.W. (2005). Assessing the Value of IT: Understanding and Measuring the Link between IT and Strategy. Information Systems Control Journal, 3(1), pp. 40-44.

[7] CIO Executive Council. (2009, December 18). Communicating IT Value. Retrieved from https://www.cio.com/article/2421917/communicating-it-value.html Last Accessed December 12, 2018.

[8] Computerweekly.com. (n.d). Understanding the real value of IT and proving it to the business. Retrieved from https://www.computerweekly.com/feature/Understanding-the-real-value-of-IT-and-proving-it-to-the-business Last Accessed December 13, 2018

[9] Daniel, D. (2007, March 31). The rising importance of the Enterprise Architect. CIO. Retrieved from http://www.cio.com/article/2439397/it-organization/the-rising-importance-of-the-enterprise-architect.html Last Accessed December 12,2018

[10] Durbin, S. (2014, August 27). Three Things CIOs should know about Cyber Security. CIO INSIGHT. Retrieved from https://www.cioinsight.com/security/three-things-cios-should-know-about-cyber-security.html Last Accessed December 13, 2018

[11] Heller, M. (2011, February 23). Helping the Business Better Understand IT. CIO Executive Council. Retrieved from https://www.cio.com/article/2410860/helping-the-business-better-understand-it.html Last Accessed December 13, 2018

[12] Hunter, R., \& Westerman, G. (2009). The Real Business of IT. How CIOs create and communicate Business value. Boston, Massachusetts: Harvard Business Press.

[13] IT governance and legal compliance strategies for CIOs. (n.d). TechTarget. Retrieved from https://searchcio.techtarget.com/feature/ITgovernance-and-legal-compliance-strategies-for-CIOs Last Accessed December 14, 2018

[14] Kirikova, M. (2015). Enterprise Architecture and Knowledge Perspectives on Continuous Requirements Engineering. REFSQ Workshops. pp. 44-51. Retrieved from https:/www.semanticscholar.org/paper/Enterprise-Architecture-and-Knowledge-PerspectivesKirikova/cd144ceb37e8e50c19d93a52d16bfbb8ffbae8be Last Accessed December 13, 2018

[15] Pose, M. (2011). Importance of IT in Business. Available Online. http://www.martinposse.com/?p=28 Last Accessed Dec. 13 , 2018

[16] Ross, J.W., Weill, P., \& Robertson, D.C. (2006). Enterprise Architecture as a Strategy. Creating a foundation for Business Execution. Boston, Massachusetts: Harvard Business School Press. Retrieved https://profesores.virtual.uniandes.edu.co/ isis1404/dokuwiki/lib/exe/fetch.php?media=bibliografia:6_enterprise_architecture_as_strat egy.pdf Last Accessed December 14, 2018

[17] Rouse, M. (n.d.). Chief Information Officer (CIO) definition. TechTarget.com. Retrieved from http://searchcio.techtarget.com/definition/CIO Last Accessed December 14, 2018 